\title{
Recognition of Astronomy as an Essential Discipline at All Levels of Education in Tanzania
}

\author{
N. T. Jiwaji \\ Open University of Tanzania, Physical Sciences Department, Faculty of Science, \\ Technology and Environmental Studies, P. O. Box 23409, Dar es Salaam, TANZANIA, Tel: \\ +255222668820,Email: ntjiwaji@yahoo.com
}

\begin{abstract}
With decreasing interest in pursuing pure science programs, the onus is on Primary and Secondary schools to attract and maintain interest of students to pursue science subjects. Misunderstanding fundamental concepts leads to misconceptions about how processes work in nature. Many decades of teaching science to children without recourse to practical and hands on activities has led to disillusionment among learners that science is difficult to comprehend. It is discussed in this paper that this phenomenon is not restricted to the East African region but has also been documented and tackled in developed countries. It is proposed that introducing astronomy as a subject at all levels of education can revive interest in science and provide hands on experiences that can assist to remove fundamental misconceptions about processes in nature.
\end{abstract}

Keywords: - Astronomy, Education, Science, Concepts, Misconceptions

\section{Introduction}

Decreasing enrolments in most science programs (Percy, 2009 and Ngaruko, et. al., 2012) is a cause of much concern because it hinders local capacity to tackle problems and challenges from nature that hinder economic development of the society. Kyomo (2011) has documented the complaints of students and teachers regarding the lack of hands-on learning Physics in Tanzania for full understanding of fundamental concepts.

A deeply internalised understanding of science as a systematic study of nature is the tool that is essential to understand the problems that nature throws at us from every corner and it is science that will lead us to solutions of these problems. The lack of hands on science teaching in Tanzania for the past decades has handicapped a whole generation of

82

Rwanda Journal, Series D, Volume 1, 2016, Life and Natural Sciences: Special issue I 
students and teachers. Teaching by rote has been the only path available to teachers. Such a situation is a recipe for disaster. An epic study in western developed countries by Sadler $(1992$, p.9) declared that "science education is a disaster in the United States of America". This was only twenty years ago in the USA; hence we also need to wake up to this fact ourselves so that we can tackle this problem head on.

\section{Literature and Discussions}

Sadler (1992) states that though most students may know science facts but will be extremely weak on concepts and applying them to solve common problems. They apparently do not have any connection with the concepts they are being taught. What can we say for our own countries in East Africa? Have we overcome this problem? "The only source of knowledge is experience" is a quote attributed to Albert Einstein. Are we immune from this? The main problem with rote teaching is the danger of developing misconceptions of basic concepts which hinder understanding of higher concepts. A student is thus left struggling, wondering why s/he should struggle so much when other much easier subjects based on more common experiences are available at school.

Sadler $(1992, \mathrm{p} 10)$ further elaborates that "Teachers become frustrated when dealing with the confusion of students who have difficulty learning simple concepts because of their faulty foundations". Yet teachers are woefully unaware of the misconceptions of their students (Sadler, 1987). A few examples of misconceptions:

- The Earth is a sphere with the upper hemisphere made of air and the ground making the lower half of the sphere

- The Sun and Moon are within our atmosphere

- Orbits of planets are egg shaped

- Hot seasons result from Earth being closer to Sun

To educate students, a teacher has to build concepts while at the same time remove misconceptions. Teachers themselves have to beware of the misconceptions they can perpetuate when they themselves do not understand the concepts deeply (Turkoglu et. al., 2009). Students who 
are used to rote learning accept concepts blindly rather than understand and internalise those concepts. Taking some examples from astronomy, we can query their understanding:

- Can they internalize the differences between heliocentric versus geocentric models?

- Can they visualize the difference between positions of the Sun in their own geocentric frame of reference with the positions is in the heliocentric frame of reference? For example, the tilt of Earth and its relation to the movement of Sun as seen from Earth during the course of a year.

Hence misconceptions are equated to faulty foundations. Without removing these misconceptions, "students are damned to place new conceptions upon faulty foundations" (Sadler, 1992, p.211)

After such a long period of stagnant science learning, our biggest challenge now is to know what is going on in our pupils' minds. Historical development of topics in astronomy provides a natural development of the thought processes that has led to understanding of the world beyond our reach. Astronomy also provides numerous examples of the scientific process where varied hypotheses emanating naturally in the minds of learners can be systematically tested (McKinnon and Geissinger, 2002; Hogan, 2009; and Impey, 2014). Astronomy provides a tool for understanding existing misconceptions while at the same time stimulating students' interest in science. Even in the US in 1997, there was concern about the need to introduce astronomy into school curriculum. Why teach astronomy to kids? Percy (2006) has listed the following reasons:

- Grasp thought processes that led to historical development of science.

- Introduce fundamental science of force and energy.

- Practical use in timekeeping, finding directions.

- Use Mathematical concepts.

- Display sophisticated technology.

- Express roots of our existence.

Teaching science through astronomy at the basic levels of Kindergarten (and at home), Primary and at Secondary levels will build foundations of

84

Rwanda Journal, Series D, Volume 1, 2016, Life and Natural Sciences: Special issue I 
science, while at Advanced Secondary, and at University and Post Graduate levels it will produce well versed teachers, researchers and thinkers.

In Tanzania, there are many problems in astronomy education that still need to be tackled (Jiwaji, 2008; URT, 2010):

- Up until 2005, astronomy concepts were included in the science curriculum in Primary schools.

- Now it only appears in the Geography part of the social studies curriculum and is touched slightly at standard 4, and the Solar System topic is taught at standard 5 with emphasis on climate.

- There are many mistakes on astronomy facts and concepts in school books by local authors.

- No astronomy is taught at Advanced Secondary level.

- No degree programs are offered in astronomy.

\section{Conclusion and Recommendations}

Even in resource rich developed countries, studies have documented serious misconceptions in understanding science. These misconceptions have to be caught early to give students a chance to understand and internalize basic concepts on which higher level concepts needed to understand nature are based. Astronomy provides an attractive discipline that incorporates all the fundamental principles of development of science concepts.

It is recommended that there is the need to recognize astronomy as discipline that can allow students to understand science principles and concepts naturally. By including astronomy as a discipline taught at all levels of education from the lowest to the highest levels in our education system, it will allow fundamental concepts in science to be understood from their roots and these can be used to understand and solve the many challenges that we face from nature.

A comprehensive survey and analysis of misconceptions hence needs to 
be conducted within our East African and African regions to assess the levels of understanding of fundamental concepts in science and mathematics among graduates, teachers and students of science and mathematics in schools and universities.

\section{References}

Hogan, K. (2009). Why Should We Teach Astronomy in High Schools? Podcast Posted by kortney.hogan on Jul 29, Accessed 23.June.2014, http://cosmoquest.org/x/365daysofastronomy/2009/07/29/july29th-why-should-we-teach-astronomy-in-high-schools/

Impey, C. (2014). Teach Astronomy, Astropedia by Astropedia/Chris Impey is licensed under a Creative Commons AttributionNonCommercial-NoDerivs 3.0 Unported License. Accessed 23.June.2014, http://www.teachastronomy.com/

Jiwaji, N. T. (2008). State of Astronomy in Tanzania and Challenges Ahead, Poster presented at the First Middle East and Africa IAU Meeting, April 5-10, 2008, Cairo, Egypt.

Kyomo, Z. (2011). Application of students' projects of constructing devices as a teaching and learning method for physics in Secondary schools in Tanzania, Master of Education thesis, Open University of Tanzania.

McKinnon, D. and Geissinger, H. (2002). Interactive Astronomy in Elementary Schools. Educational Technology \& Society, 5 (1), ISSN 1436-4522, Accessed 23.June.2014, http://www.ifets.info/journals/5_1/mckinnon.html

Ngaruko, D. D., Saria, J. A. and Jiwaji, N. T. (2011) Factors Associated with Undergraduate Performance in ODL institutions: A Spotlight on Mathematics and Physical Sciences at the Open University of Tanzania, Proceedings of the 3rd ACDE Conference from 12th - 15th July 2011, Dares- Salaam, Tanzania.

Percy, J. R. (2006). Teaching Astronomy: Why and How?, Part 5: Percy, JAAVSOVolume 35, 2006, Accessed 23.June.2014, http://www.aavso.org/files/webpublications/ejaavso/v35n1/248.p $d f$

86

Rwanda Journal, Series D, Volume 1, 2016, Life and Natural Sciences: Special issue I 
Percy, J. R. (2009). Teaching and Learning Astronomy, Review paper presented to the conference "Mathematics and Astronomy: A Joint Long Journey" Madrid. Accessed 23.June.2014 http://www.astro.utoronto.ca/ percy/madrid.pdf

Sadler, P. M. (1987). Misconceptions in Astronomy. In 2nd International Seminar on Misconception and Educational Strategies in Science and Mathematics in Ithaca, NY, ed. by Joseph D. Novak. Ithaca, NY: Cornell University Press, pp. 422-425.

Sadler, P. M.(1992). The Initial Knowledge State of High School Astronomy Students, A Dissertation Presented to the Faculty of the Graduate School of Education of Harvard University in Partial Fulfillment of the Requirements for the Degree of Doctor of Education, Accessed 23.June.2014. http://www.cfa.harvard.edu/sed/staff/Sadler/articles/Sadler\%20 Dissertation.pdf

Turkoglu, O.,Ornek, F.,Gokdere, ., Suleymanoglu, N. and Orbay, M. (2009). On pre-service science teachers' preexisting knowledge levels about basic astronomy concepts. International Journal of Physical Sciences, Vol. 4 (11), pp. 734-739, Available online,Accessed 20.Jan.2015 at http://www.academicjournals.org/ijps, ISSN 1992 - 1950 @ 2009 Academic Journals,

URT (2010). Tanzania Physics Secondary School Syllabus, Form I-IV, United Republic of Tanzania, Ministry of Education and Vocational Training, Tanzania Institute of Education, ISBN 978 9976612387. 